\title{
DAMPAK SUBSIDI SOLAR TERHADAP KELESTARIAN SUMBER DAYA IKAN DI BITUNG, SULAWESI UTARA
}

\author{
Yesi Dewita Sari, Estu Sri Luhur dan Armen Zulham \\ Balai Besar Penelitian Sosial Ekonomi Kelautan dan Perikanan \\ JI. KS. Tubun Petamburan VI Jakarta 10260 \\ Telp. (021) 53650162, Fax. (021)53650159 \\ Diterima 21 Februari 2011 - Disetujui 4 Juni 2012
}

\begin{abstract}
ABSTRAK
Penelitian bertujuan mengetahui dampak penetapan subsidi harga solar terhadap kelestarian sumber daya ikan telah dilakukan di Pelabuhan Perikanan Samudera Bitung Kota Bitung pada Bulan April, Agustus dan Oktober 2010. Analisis pendugaan parameter biologi dilakukan dengan menggunakan model surplus produksi berdasarkan metode Clark, Yoshimoto and Pooley (CYP). Adapun analisis dinamika dan hubungan sebab akibat antara eksploitasi sumber daya perikanan dengan usaha penangkapan ikan dilakukan dengan metode analisis sistem dinamik. Hasil penelitian menunjukkan bahwa pada kondisi baseline (harga solar Rp 4.500 per liter), rata-rata harga ikan $\mathrm{Rp} 6.200$ per kg dan biaya operasional Rp 14.924.373 per trip maka jumlah effort yang diperbolehkan adalah sebanyak 1.601 trip per bulan dan jumlah produksi 982 ton per bulan serta ketersediaan stok ikan 1.306 ton. Tanpa subsidi solar (Rp 7.500 per liter) maka terjadi peningkatan biaya operasional per trip sebesar 36,76\% (Rp 20.410 .696 per trip), sedangkan jumlah effort yang diperbolehkan relatif tetap (1.600 trip per bulan). Hasil ini menunjukkan bahwa kebijakan subsidi solar tidak memberikan dampak signifikan terhadap kelestarian sumber daya ikan di Bitung. Oleh karena itu, subsidi solar harus tetap diberikan kepada nelayan di Bitung agar mereka dapat melakukan pemanfaatan sumber daya ikan secara berkelanjutan disamping mengurangi potensi pemanfaatannya oleh nelayan negara tetangga secara ilegal.
\end{abstract}

Kata Kunci: : subsidi harga solar, bioekonomi, kelestarian sumber daya ikan, Bitung

Abstract : Impact of Fuel Subsidy on Sustainablity to Fishery Resources in Bitung, North Sulawesi. By : Yesi Dewita Sari, Estu Sri Luhur and Armen Zulham.

The study aims to determine the impact of diesel price fixing subsidy to sustainability of fish resources has been carried out in the port of Ocean Fishery Bitung, Bitung City in April, August and October 2010. Analysis of biological parameter estimation is done using a production surplus model based on the method of Clark, Yoshimoto and Pooley (CYP). The analysis of the dynamics and the causal relationship between the exploitation of fishery resources to fishing effort carried out by the method of dynamical systems analysis. The results showed that in the baseline condition (diesel price of $R p$ 4,500 per liter), the average price of $R p$ 6,200 per $\mathrm{kg}$ of fish and operational costs $R p$ 14,924,373 per trip allowed the amount of effort that is as much a 1601 trips per month and the amount of production of 982 tons per month, and 1306 tons of fish stocks. Without the solar subsidy (Rp 7,500 per liter), then an increase in operating costs per trip by $36.76 \%$ (Rp 20,410,696 per trip), while the amount of effort that allowed relatively fixed (1,600 trips per month). These results indicate that the diesel subsidy policy does not provide a significant impact on the sustainability of fish resources in Bitung. Therefore, solar subsidies should be given to fishermen in Bitung so that they can perform the utilization of fish resources in a sustainable manner as well as reducing the potential for use by fishermen neighboring countries illegally.

Keywords: diesel price subsidy, bioeconomic, sustainable resources, Bitung 


\section{PENDAHULUAN}

Sumber daya perikanan merupakan aset alam yang diekstraksi untuk memberikan manfaat sebesar-besarnya bagi manusia. Manfaat tersebut terdiri dari manfaat ekonomi, ekologi dan sosial yang saling berkaitan. Untuk mencapai manfaat tersebut, maka dalam pemanfaatan sumber daya perikanan diperlukan pengaturan-pengaturan dalam pengelolaan karena tanpa pengaturan yang benar maka sumber daya perikanan tersebut akan dapat punah. Beberapa instrumen dapat diterapkan dalam pengelolaan perikanan. Salah satu instrumen pengelolaan sumber daya perikanan yang hangat diperbincangkan dunia internasional yaitu adanya pemberian subsidi dalam melakukan usaha penangkapan ikan.

Pemberian subsidi perikanan merupakan salah satu campur tangan pemerintah dalam sektor kelautan dan perikanan dengan tujuan meningkatkan kesejahteraan masyarakat atau nelayan. Pemberian subsidi pada sektor perikanan di satu sisi akan meningkatkan upaya penangkapan yang berdampak pada peningkatan produksi. Di sisi lain, WTO menilai, pemberian subsidi akan meningkatkan laju pengambilan atau ekstraksi sumber daya ikan yang mengakibatkan perikanan dalam kondisi overcapacity dan overfishing (Fauzi, 2005).

Diskusi mengenai subsidi perikanan berlangsung sangat intensif, baik pada tingkat nasional maupun tingkat internasional. Pada tingkat nasional tersebut terkait: pertama, strategi yang harus diambil dalam mengantisipasi kesepakatan atau ratifikasi perjanjian internasional yang terkait dengan perdagangan dan subsidi. Kedua, program pembangunan yang terkait dengan skema subsidi perikanan.

Pada tingkat internasional, kebijakan subsidi perikanan nasional ini menjadi bumerang, jika hasil perikanan tersebut diperdagangkan di negara lain. Namun, kini kebijakan subsidi perikanan berkembang bukan lagi terkait dengan perdagangan, tetapi merambah ke isu sosial ekonomi masyarakat perikanan termasuk pengelolaan sumber daya dan ketahanan pangan (Mathew, 2003). Jika dicermati seperti yang diungkapkan Schrank (2001) inti dari subsidi perikanan tersebut terkait dengan: (1) distribusi pendapatan; dan (2) keberlanjutan sumber daya dan usaha perikanan. Inti dari substansi subsidi perikanan yang didiskusikan tersebut, ternyata subsidi perikanan dapat berpengaruh positif dan negatif terhadap pertumbuhan sektor perikanan dalam jangka pendek dan jangka panjang.

Strategi mengalokasikan subsidi perikanan menjadi simpul penting agar berdampak positif terhadap pembangunan perikanan. Dengan demikian, subsidi perikanan yang efektif seharusnya merupakan subsidi yang dapat menjaga kelestarian potensi sumberdaya ikan, menjaga kestabilan produksi perikanan, serta mendorong kesejahteraan masyarakat. Penelitian ini bertujuan untuk mengetahui dampak pemberian subsidi harga solar terhadap kelestarian sumber daya ikan.

\section{METODE PENELITIAN}

\section{Lokasi dan Waktu Penelitian}

Penelitian dilakukan di Pelabuhan Perikanan Samudera Bitung, Kota Bitung, Provinsi Sulawesi Utara. Nelayan yang mendaratkan ikan hasil tangkapan di PPS Bitung sebagian besar melakukan penangkapan ikan di Laut Sulawesi dan Samudera Pasifik. Pengumpulan data dilakukan pada Bulan April, Agustus dan Oktober tahun 2010.

\section{Jenis, Sumber dan Cara Pengumpulan Data}

Jenis data yang digunakan dalam penelitian ini terdiri data primer dan data sekunder. Data primer diperoleh dari hasil wawancara langsung dengan nelayan di Bitung menggunakan panduan kuesioner. Data primer berupa seluruh komponen biaya yang dikeluarkan dalam melakukan usaha penangkapan ikan. Jumlah responden sebanyak 35 orang yang terdiri dari nelayan dengan 
menggunakan alat tangkap purse seine, pole and line dan tuna hand line. Data sekunder berupa data runtun waktu jumlah upaya penangkapan, jumlah produksi dan perkembangan harga ikan yang didaratkan. Data runtun waktu jumlah upaya penangkapan dan jumlah produksi dikumpulkan selama 5 tahun yang berupa data bulanan mulai Bulan Januari 2005 sampai dengan Bulan Desember 2009. Data harga ikan yang digunakan adalah rata-rata harga ikan dominan di daratkan di Bitung selama tahun 2009. Ikan dominan tersebut terdiri dari ikan layang, kembung, cakalang dan tuna. Data sekunder diperoleh dari Dinas Kelautan dan Perikanan Kota Bitung dan Pelabuhan Perikanan Samudera Bitung.

\section{Metode Analisis Data}

Metode analisis data terdiri dari metode untuk pendugaan parameter-parameter yang digunakan dan metode untuk pendugaan nilai optimal pemanfaatan sumber daya perikanan di Bitung dengan dan tanpa subsidi harga solar. Parameter yang digunakan dalam penelitian ini meliputi parameter biologi dan parameter ekonomi. Parameter biologi yang diduga adalah parameter pertumbuhan intrinsik ikan ( $r$ ), daya dukung lingkungan (K) dan kemampuan alat tangkap dalam melakukan penangkapan ikan (q). Parameter ekonomi yaitu rata-rata harga ikan dominan dan biaya operasional berdasarkan jenis alat tangkap.

Parameter biologi diduga dengan menggunakan model surplus produksi yang dikemukakan Clark, Yoshimoto and Pooley (1992) dalam Tinungki, 2005 lebih dikenal dengan metode CYP. Persamaan CYP dalam bentuk matematis dapat ditulis sebagai berikut :

$$
\ln \left(U_{t+1}\right)=\frac{2 r}{(2+r)} \ln (q K)+\frac{(2-r)}{2+r} \ln \left(U_{t}\right)-\frac{q}{(2+r)}\left(E_{t}+E_{t+1}\right)
$$

dimana :

$$
U_{t}=\frac{h_{t}}{E}
$$

$r=$ Tingkat pertumbuhan intrinsik/ Intrinsic
growth rate

$\mathrm{q}=$ Koefisien kemampuan tangkap/ Catchability coefficient

K = Daya dukung perairan/Carrying capacity

$E_{t}=$ Upaya penangkapan/ Effort

Dengan meregresikan hasil tangkap per unit input (effort) yang dilambangkan dengan $U$ pada periode $t+1$ dan dengan $U$ pada periode $t$, serta penjumlahan input pada periode $t$ dan $t+1$, akan diperoleh koefisien $r$, q dan $\mathrm{K}$ secara terpisah. Selanjutnya setelah disederhanakan persamaan diatas dapat diestimasikan dengan OLS melalui :

$$
\operatorname{Ln}\left(U_{t+1}\right)=C_{1}+C_{2} \ln \left(U_{t}\right)+C_{3}\left(E_{t}+E_{t+1}\right)
$$

Sehingga nilai parameter $r, q$ dan $\mathrm{K}$ dapat diperoleh melalui persamaan berikut :

$$
\begin{aligned}
\mathrm{r} & =\frac{2(1-C 2)}{(1+C 2)} \\
\mathrm{q} & =-C_{3}(2+r) \\
\mathrm{K} & =\frac{e^{C_{1}(2+r) /(2 r)}}{q}
\end{aligned}
$$

Dalam menentukan jumlah effort (upaya penangkapan) yang digunakan terlebih dahulu dilakukan standarisasi terhadap upaya penangkapan tersebut. Standarisasi dilakukan untuk memperoleh jumlah alat tangkap yang mempunyai hasil tangkapan per unit upaya penangkapan yang sama. Dalam penelitian ini, standarisasi alat tangkap yang dilakukan mengacu kepada metode yang dikemukakan oleh Tampubolon et al., (1983) dalam Tinungki (2005). Metode standarisasi alat tangkap tersebut adalah; 
$C P U E_{s t}=\frac{C_{s t}}{E_{s t}}$

$F P I_{s t}=\frac{C P U E_{s t}}{C P U E_{s t}}$

$C P U E_{i}=\frac{C_{i}}{E_{i}}$

$F P I_{i}=\frac{C P U E_{i}}{C P U E_{s t}}$

dimana:

$C_{\S} \quad: \quad$ Jumlah hasil tangkapan alat standar / Catch of standart fishing gear

$C_{i} \quad: \quad$ Jumlah hasil tangkapan alat i) Catch of i fishing gear

$E_{s} \quad: \quad J u m l a h$ upaya penangkapan alat standar / Effort of fishing gear

$E_{i} \quad: \quad$ Jumlah upaya penangkapan alat $i$ / Effort of $i$ fishing gear

FPI : Fishing power indeks alat standar / Fishing power index of standart fishing gear

$F_{i} \quad$ : Fishing power indeks alat i / Fishing power index of $i$ fishing fear

$C P U E_{\S}:$ Hasil tangkapan per upaya penangkapan alat standar / Catch per unit effort of standart fishing gear

CPUE $E_{i}$ : Hasil tangkapan per upaya penangkapan alat $i$ /Catch per unit effort of $i$ fishing gear

Parameter harga dan biaya dalam penelitian ini diasumsikan konstan. Pendugaan harga ikan hasil tangkapan diperoleh dari data sekunder. Komponen biaya yang digunakan terdiri dari biaya investasi, biaya variabel dan biaya tetap.

Pendugaan nilai optimal pada pemanfaatan sumber daya perikanan di Bitung secara ekonomi terdiri dari pendugaan terhadap jumlah upaya penangkapan, jumlah hasil tangkapan dan biomasa atau stok ikan.
Pendugaan nilai optimal menggunakan fungsi pertumbuhan logistik $F(x)=x\left(1-\frac{x}{K}\right)$,Schaefer, 1954) dan fungsi pertumbuhan $h=q E X$. Pendugaan untuk masing-masing variabel tersebut adalah:

$E=\frac{r}{2 q}\left(1-\frac{c}{p q K}\right)$

dimana :

$\mathrm{c}$ = Biaya penangkapan / Fishing cost

$\mathrm{p}=$ Harga ikan / Fish price

Dengan mensubstitusikan nilai $\mathrm{E}$ ke persamaan h, maka akan diperoleh jumlah hasil tangkapan

$h^{*}=\frac{r K}{4}\left(1+\frac{c}{p q K}\right)\left(1-\frac{c}{p q K}\right)$ dan jumlah

biomas adalah sebagai berikut:

$x^{*}=\frac{h}{q \cdot E}$

dimana :

$h^{*}=$ Jumlah hasil tangkapan optimal/ Optimal total catch

$x^{*}=$ Jumlah biomassa optimal/ Optimal total biomass

Lebih jauh untuk mengetahui dampak subsidi terhadap kelestarian sumber daya perikanan dalam jangka waktu beberapa tahun ke depan dilakukan analisis sistem dinamik. Penggunaan metode sistem dinamik ini merupakan salah satu cara penyelesaian persoalan (permasalahan) yang mengimplikasikan sebuah struktur yang terdiri dari fungsi-fungsi yang saling berinteraksi dalam suatu hubungan sebab akibat (umpan balik) sehingga membentuk karakteristik dan perilaku sistem. Interaksi yang terjadi dalam struktur ini diterjemahkan ke dalam model-model matematik yang selanjutnya dengan bantuan komputer digital disimulasikan untuk memperoleh perilaku historis (Wirabhuana, 2005). 


\section{HASIL DAN PEMBAHASAN}

\section{Profil Lokasi Penelitian}

Kota Bitung berada pada posisi geografis $1^{\circ} 23^{\prime} 23^{\prime \prime}$ - 1 1 $35^{\prime} 39 \mathrm{LU}$ dan $125^{\circ} 1^{\prime} 43^{\prime \prime}$ - 126 $16^{\circ} 13^{\prime \prime}$ $\mathrm{BT}$, dengan luas wilayah darat $31.350,35 \mathrm{ha}$, luas wilayah laut $714 \mathrm{~km} 2$, dan panjang garis pantai 143,2 km. Batas-batas wilayah Kota Bitung adalah di sebelah utara berbatasan dengan Kabupaten Minahasa Utara dan Laut Sulawesi, sebelah selatan dan timur berbatasan dengan Laut Maluku, dan sebelah barat berbatasan dengan Kabupaten Minahasa Utara. Jumlah penduduk Kota Bitung tahun 2009 diestimasikan sebanyak 202.962 jiwa.

Sumber daya perikanan Indonesia khususnya Wilayah Pengelolaan Perikanan (WPP) 715 dan 716 berdasarkan Permen KP no 1 tahun 2009 masih berstatus moderat untuk perikanan demersal dan pelagis kecil serta fully exploited untuk perikanan pelagis besar. Kapal perikanan yang melakukan penangkapan di WPP tersebut sebagian besar berpangkalan di Pelabuhan Perikanan Samudera (PPS) Bitung, Sulawesi Utara.

Bitung memiliki sumber daya perikanan yang cukup potensial, potensi penangkapan di Sulawesi Utara pada perairan 12 mil seluas $314,98 \mathrm{~km}^{2}$ dan produksi 125,9 ton per tahun. Pada perairan zona ekonomi eksklusif seluas $190 \mathrm{~km}^{2}$ produksi mencapai 196,9 ton per tahun. Armada penangkapan ikan dilihat dari jumlah kapal selama 10 tahun terakhir menunjukkan penurunan dengan rata-rata penurunan $4,81 \%$ per tahun. Penurunan ini terlihat karena adanya penurunan jumlah perahu tanpa motor dalam jumlah yang signifikan. Penurunan jumlah perahu tanpa motor ini disebabkan karena sebagian nelayan telah memiliki perahu dengan motor tempel.

Alat tangkap yang dominan di Bitung adalah hand line yaitu alat tangkap yang digunakan untuk menangkap ikan tuna. Kapal kurang dari 5 GT dengan alat tangkap hand line mampu melakukan penangkapan di ZEEI dengan ikan hasil tangkapan tuna berukuran lebih dari $35 \mathrm{~kg}$ per ekor. Selain alat tangkap hand line, alat tangkap yang banyak dijumpai di Kota Bitung adalah alat tangkap purse seine untuk menangkap ikan pelagis kecil dan alat tangkap pole and line untuk menangkap ikan cakalang (Tabel 1).

Jumlah nelayan yang terlibat di dalam sebuah kapal penangkap ikan tergantung dari jenis alat tangkap yang digunakan. Pada alat tangkap purse seine dan pole and line, ratarata jumlah nelayan yang terlibat sebanyak 25 orang per kapal per trip. Sedangkan untuk kapal dengan alat tangkap hand line memerlukan ABK lebih banyak untuk ukuran kapal yang lebih besar. Kapal dengan alat tangkap hand line yang berukuran kurang dari 10 GT hanya memerlukan ABK sebanyak 7 orang, sedangkan untuk kapal dengan alat tangkap yang pada ukuran lebih dari 10 GT memerlukan ABK sebanyak 20 orang. Selain kapal penangkap ikan, kapal pengangkut yang terdapat di Kota Bitung berjumlah sekitar $2 \%$ dari total kapal.

Jenis ikan dominan yang didaratkan di PPS Bitung adalah ikan cakalang, tuna, layang. Jumlah produksi ikan cakalang dan ikan tuna di Bitung selalu menunjukkan peningkatan. Peningkatan jumlah produksi ikan cakalang sebesar 6,36\% per tahun. Produksi ikan tuna mengalami peningkatan sebesar 2,48\% dari tahun 2007 ke tahun 2008, dan mengalami peningkatan yang cukup besar dari tahun 2008 ke tahun 2009 sebesar 9,94\%. Jika dirata-rata, peningkatan produksi ikan tuna periode 2007-2009 adalah sebesar $6,21 \%$ per tahun. Jumlah produksi ikan layang mengalami peningkatan dari tahun 2007 ke tahun 2008 yaitu 10,20\%, tetapi mengalami penurunan yang cukup signifikan dari tahun 2008 ke tahun 2009 sebesar $21,65 \%$.

Alat tangkap purse seine merupakan jenis alat tangkap yang memberikan hasil tangkapan tertinggi di PPS Bitung. Rata-rata jumlah hasil tangkapan dengan menggunakan alat tangkap purse seine selama 2005-2009 adalah $78,57 \%$ dari total hasil tangkapan yang didaratkan di PPS Bitung. 
Tabel 1. Jumlah Kapal dan Jumlah Nelayan Menurut Jenis Alat Tangkap di Bitung, Tahun 2009. Table 1. Number of Vessels and Fisherman by Fishing Gear Types in Bitung, 2009.

\begin{tabular}{|c|c|c|c|}
\hline $\begin{array}{c}\text { Kategori } \\
\text { Kapal /Vessel } \\
\text { Category }\end{array}$ & $\begin{array}{l}\text { Alat Tangkap/ } \\
\text { Fishing Gear Types }\end{array}$ & $\begin{array}{l}\text { Jumlah Kapal/ } \\
\text { Number Of Vessel }\end{array}$ & $\begin{array}{l}\text { Jumlah Nelayan/ } \\
\text { Number Of Fisherman }\end{array}$ \\
\hline \multirow{2}{*}{$\begin{array}{l}\text { Tanpa Motor/ } \\
\text { vessel without } \\
\text { engine }\end{array}$} & Pancing ulur/Hand Line & 525 & 1,050 \\
\hline & Jumlah/Total & 525 & 1,050 \\
\hline \multirow[t]{9}{*}{$<5 \mathrm{GT}$} & Pancing ulur/Tuna Hand Line & 50 & 250 \\
\hline & Pukat cincin/Purse Seine & 5 & 100 \\
\hline & Bagan Apung/ Chart Floating & 1 & 1 \\
\hline & Sero Jaring/Set Net & 2 & 4 \\
\hline & Sero Tanam/Sero planting & 1 & - \\
\hline & Huhate/Pole and line & - & - \\
\hline & Perahu lampu/Light Boat & 8 & 32 \\
\hline & Pengangkut/Penampung/ courier & - & - \\
\hline & Jumlah/Total & 67 & 387 \\
\hline \multirow[t]{5}{*}{$6-10 \mathrm{GT}$} & Pancing ulur/Hand Line & 63 & 441 \\
\hline & Pukat cincin/Purse Seine & 50 & 1,250 \\
\hline & Perahu lampu/Light Boat & 16 & 64 \\
\hline & Pengangkut/Penampung/Courier & 3 & 18 \\
\hline & Jumlah/total & 132 & 1,773 \\
\hline \multirow[t]{7}{*}{$11-30 \mathrm{GT}$} & Pancing ulur/Hand Line & 33 & 660 \\
\hline & Pukat cincin/Purse Seine & 19 & 475 \\
\hline & Huhate/Pole and line & 5 & 125 \\
\hline & Pancing rawai/Tuna long line & 9 & 135 \\
\hline & Perahu lampu/Light Boat & 24 & 120 \\
\hline & Pengangkut/Penampung/Courier & 24 & 240 \\
\hline & Jumlah/Total & 114 & 1,755 \\
\hline \multirow[t]{11}{*}{$>30 \mathrm{GT}$} & Pancing ulur/Hand Line & 18 & 360 \\
\hline & Pukat cincin/Purse Seine & 65 & 1,625 \\
\hline & Huhate/Pole and line & 47 & 1,175 \\
\hline & Pancing rawai/Tuna long line & 98 & 1,470 \\
\hline & $\begin{array}{l}\text { Pancing rawai dasar/Bottom long } \\
\text { line }\end{array}$ & 16 & 320 \\
\hline & Pukat Ikan/Fish net & 16 & 400 \\
\hline & Jaring insang/Gill Net & 23 & 690 \\
\hline & Perahu lampu/Light Boat & 1 & 5 \\
\hline & Pengangkut/Penampung/Courier & 164 & 2,460 \\
\hline & Jumlah/Total & 448 & 8,505 \\
\hline & Jumlah /Total & 1,286 & 13,470 \\
\hline
\end{tabular}

Sumber: PPS Bitung (2010) / Source: PPS Bitung (2010) 
Rata-rata jumlah hasil tangkapan menggunakan alat tangkap huhate adalah $20,33 \%$ dari total hasil tangkapan. Persentase jumlah hasil tangkapan purse seine dalam selang waktu 5 tahun menunjukkan angka yang semakin menurun, sedangkan persentase jumlah hasil tangkapan huhate semakin meningkat. Hal ini disebabkan karena semakin meningkatnya jumlah nelayan yang menggunakan alat tangkap huhate untuk menangkap jenis ikan cakalang (Tabel 2). dengan bobot lebih dari 20 GT dominan menggunakan alat tangkap untuk menangkap ikan cakalang dan tuna. Standar effort yang digunakan dalam penelitian ini adalah jumlah kunjungan perahu motor tempel ditambah dengan kapal motor kurang dari 20 GT. Jumlah hasil tangkapan per unit effort standar (CPUE standar) adalah jumlah kunjungan perahu motor tempel ditambah dengan kapal motor berbobot sampai 20 GT dibagi dengan jumlah hasil tangkapan purse seine.

Tabel 2. Jumlah Hasil Tangkapan Berdasarkan Jenis Alat Tangkap di Bitung, 2005-2009.

Table 2. Total Fish Catched per of Productions Based on Fishing Gear Type, Bitung 2005-2009.

\begin{tabular}{llrrrrr}
\hline & Jenis Alat Tangkap/ & \multicolumn{5}{c}{ Tahun/ Year } \\
\cline { 2 - 7 } & Fishing Gear Type & \multicolumn{1}{c}{$\mathbf{2 0 0 5}$} & $\mathbf{2 0 0 6}$ & $\mathbf{2 0 0 7}$ & $\mathbf{2 0 0 8}$ & \multicolumn{1}{c}{$\mathbf{2 0 0 9}$} \\
\hline 1 & Pukat Cincin/Purse Seine & $5,026.12$ & $7,333.98$ & $5,065.32$ & $9,883.84$ & $10,248.96$ \\
2 & Huhate/Pole and Line & 603.56 & $1,434.37$ & $1,500.26$ & $3,010.24$ & $4,383.21$ \\
3 & Pancing Ulur/Hand Line & 1.42 & 0.51 & 0.51 & 4.33 & 57.30 \\
5 & Jaring Insang /Gill Net & - & - & - & 110.00 & 320.61 \\
6 & Rawai Tuna /Long Line & - & - & - & - & 330.23 \\
\hline & Jumlah /Total (Ton) & $\mathbf{5 , 6 3 1 . 1 0}$ & $\mathbf{8 , 7 6 8 . 8 6}$ & $\mathbf{6 , 5 6 6 . 0 9}$ & $\mathbf{1 3 , 0 0 8 . 4 1}$ & $\mathbf{1 5 , 3 4 0 . 3 1}$ \\
\hline
\end{tabular}

Sumber: PPS Bitung (2010) / Source: PPS Bitung (2010)

Berdasarkan informasi diatas, dalam analisis selanjutnya menggunakan alat tangkap purse seine sebagai alat tangkap standar. Purse seine merupakan jenis alat tangkap yang melakukan penangkapan 1 hari (one day fishing), dengan demikian dapat disimpulkan bahwa kapal dengan alat tangkap purse seine merupakan armada penangkapan dengan kunjungan tertinggi. Data pada penelitian ini berupa jumlah hasil tangkapan menurut jenis alat tangkap dan jumlah kunjungan kapal terdiri dari perahu tanpa motor, perahu motor tempel dan kapal motor. Perahu tanpa motor menggunakan alat tangkap jaring dan pancing dengan jumlah hasil tangkapan yang sedikit. Perahu motor tempel dan kapal motor dengan bobot sampai 20 GT dominan menggunakan alat tangkap purse seine. Sedangkan kapal motor
CPUE perahu tanpa motor diperoleh dari jumlah kunjungan perahu tanpa motor dibagi dengan jumlah produksi dari alat tangkap lain-lain. CPUE kapal motor dengan bobot lebih dari 20 GT diperoleh dari jumlah kunjungan kapal lebih dari 20 GT dibagi dengan jumlah produksi alat tangkap huhate, rawai tuna dan gillnet. Jumlah produksi, jumlah kunjungan kapal dengan menggunakan purse seine sebagai alat tangkap standar dan CPUE per bulan disajikan pada Tabel 3. Rata-rata produksi ikan di PPS Bitung selama 60 bulan mulai bulan Januari 2005 sampai dengan Desember 2009 adalah 993,4 ton per bulan. Rata-rata jumlah kunjungan kapal purse seine setiap bulan adalah 1.562 kali. Rata-rata jumlah hasil tangkapan setiap kunjungan kapal (CPUE) di PPS Bitung adalah 0,64 ton (Tabel 3). 
Tabel 3. Jumlah Produksi dan Jumlah Kunjungan Kapal ke PPS Bitung, 2010.

Table 3. Total Catched of Production and Vessel Visits to PPS Bitung, 2010.

\begin{tabular}{|c|c|c|c|c|}
\hline $\begin{array}{l}\text { Tahun/ } \\
\text { Year }\end{array}$ & $\begin{array}{l}\text { Bulan/ } \\
\text { Month }\end{array}$ & $\begin{array}{l}\text { Produksi/ } \\
\text { Production }\end{array}$ & $\begin{array}{c}\text { Kunjungan kapal/ } \\
\text { Vessel visits }\end{array}$ & CPUE \\
\hline \multirow[t]{12}{*}{2005} & Januari/ January & 108.45 & 881 & 0.12 \\
\hline & Februari/ February & 318.35 & 413 & 0.77 \\
\hline & Maret/ March & 512.95 & 411 & 1.25 \\
\hline & April/ April & 359.80 & 520 & 0.69 \\
\hline & Mei/ May & 502.00 & 395 & 1.27 \\
\hline & Juni/ June & 622.95 & 491 & 1.27 \\
\hline & Juli/ July & 673.55 & 374 & 1.80 \\
\hline & Agustus/ August & 665.54 & 332 & 2.01 \\
\hline & September/September & $1,043.36$ & 356 & 2.93 \\
\hline & Oktober/ October & 589.82 & 283 & 2.08 \\
\hline & November/ November & 312.25 & 232 & 1.35 \\
\hline & Desember/ December & 341.80 & 235 & 1.46 \\
\hline \multirow[t]{12}{*}{2006} & Januari/ January & 535.25 & 330 & 1.62 \\
\hline & Februari/ February & 272.99 & 555 & 0.49 \\
\hline & Maret/ March & 680.67 & 968 & 0.70 \\
\hline & April/ April & 402.17 & 566 & 0.71 \\
\hline & Mei/ May & 829.00 & 920 & 0.90 \\
\hline & Juni/ June & 913.14 & 1,016 & 0.90 \\
\hline & Juli/ July & 761.03 & 1,658 & 0.46 \\
\hline & Agustus/ August & $1,026.97$ & 1,443 & 0.71 \\
\hline & September/September & $1,476.86$ & 1,422 & 1.04 \\
\hline & Oktober/ October & $1,034.63$ & 1,421 & 0.73 \\
\hline & November/ November & $1,114.93$ & 1,625 & 0.69 \\
\hline & Desember/ December & 666.46 & 1,211 & 0.55 \\
\hline \multirow[t]{11}{*}{2007} & Januari/ January & 524.30 & 1,339 & 0.39 \\
\hline & Februari/ February & 298.76 & 1,039 & 0.29 \\
\hline & Maret/ March & 588.70 & 1,019 & 0.58 \\
\hline & April/ April & 992.70 & 1,017 & 0.98 \\
\hline & Mei/ May & 680.35 & 978 & 0.70 \\
\hline & Juni/ June & 772.70 & 1,056 & 0.73 \\
\hline & Juli/ July & $1,011.95$ & 1,541 & 0.66 \\
\hline & Agustus/ August & $1,162.40$ & 1,611 & 0.72 \\
\hline & September/September & $3,419.54$ & 2,807 & 1.22 \\
\hline & Oktober/ October & $1,787.80$ & 2,930 & 0.61 \\
\hline & November/ November & 822.94 & 5,450 & 0.15 \\
\hline
\end{tabular}


Lanjutan Tabel 3/Continue Table 3.

\begin{tabular}{|c|c|c|c|c|}
\hline $\begin{array}{l}\text { Tahun/ } \\
\text { Year }\end{array}$ & $\begin{array}{l}\text { Bulan/ } \\
\text { Month }\end{array}$ & $\begin{array}{l}\text { Produksi/ } \\
\text { Production }\end{array}$ & $\begin{array}{c}\text { Kunjungan kapal/ } \\
\text { Vessel visits }\end{array}$ & CPUE \\
\hline & Desember/December & $1,060.22$ & 1,279 & 0.83 \\
\hline \multirow[t]{12}{*}{2008} & Januari/ January & 889.62 & 1,762 & 0.50 \\
\hline & Februari/ February & $1,095.38$ & 1,275 & 0.86 \\
\hline & Maret/ March & $1,150.88$ & 1,195 & 0.96 \\
\hline & April/ April & $1,286.15$ & 1,229 & 1.05 \\
\hline & Mei/ May & 613.17 & 1,184 & 0.52 \\
\hline & Juni/ June & 991.95 & 1,208 & 0.82 \\
\hline & Juli/ July & 982.51 & 1,860 & 0.53 \\
\hline & Agustus/ August & $2,566.67$ & 1,896 & 1.35 \\
\hline & September/September & $1,594.84$ & 3,979 & 0.40 \\
\hline & Oktober/ October & $1,319.07$ & 3,971 & 0.33 \\
\hline & November/ November & $1,694.00$ & 8,128 & 0.21 \\
\hline & Desember/ December & 936.16 & 1,443 & 0.65 \\
\hline \multirow[t]{12}{*}{2009} & Januari/ January & $1,251.00$ & 1,786 & 0.70 \\
\hline & Februari/ February & 675.78 & 2,065 & 0.33 \\
\hline & Maret/ March & 900.72 & 3,458 & 0.26 \\
\hline & April/ April & $1,203.55$ & 1,247 & 0.97 \\
\hline & Mei/ May & $1,099.36$ & 1,638 & 0.67 \\
\hline & Juni/ June & $1,215.56$ & 2,757 & 0.44 \\
\hline & Juli/ July & $1,144.71$ & 3,000 & 0.38 \\
\hline & Agustus/ August & $1,280.87$ & 3,102 & 0.41 \\
\hline & September/September & $1,920.12$ & 1,279 & 1.50 \\
\hline & Oktober/ October & $1,915.41$ & 1,714 & 1.12 \\
\hline & November/ November & $1,347.50$ & 983 & 1.37 \\
\hline & Desember/ December & $1,644.23$ & 1,468 & 1.12 \\
\hline Rata-rata & & 993.44 & 1,562 & 0.64 \\
\hline
\end{tabular}

Sumber: PPS Bitung (2010) / Source: PPS Bitung

\section{Pendugaan Parameter}

Untuk mengetahui pengaruh subsidi terhadap kelestarian sumber daya perikanan dilakukan analisis bioekonomi pada kondisi dengan dan tanpa subsidi. Dengan melakukan analisis OLS sederhana, maka diperoleh nilai intersept $(C 1=0,17)$, koefisien $\operatorname{Ln} U(C 2=0,14)$ dan koefisien penjumlahan upaya penangkapan periode $t$ dan $t+1 \quad(C 3=-0,00013)$, serta nilai
R- square yang diperoleh $40 \%$. Setelah nilai C1, C2 dan C3 diperoleh selanjutnya dapat diduga nilai parameter $\mathrm{r}, \mathrm{K}$ dan $\mathrm{q}$. Parameter $r$ atau tingkat pertumbuhan intrinsik sumber daya perikanan di fishing ground nelayan yang mendaratkan ikan hasil tangkapan di PPS Bitung adalah $1,51 \%$ dan daya dukung lingkungan adalah 2.607 ton per bulan. Secara lengkap parameter biologi sumber daya perikanan di Bitung disajikan pada Tabel 4. 
Tabel 4 Parameter Biologi Sumber Daya Perikanan di Bitung, 2010. Table 4. Fisheries Resources Biological Parameters of Bitung, 2010.

\begin{tabular}{|c|c|c|c|}
\hline No & Koefisien/ Coefficient & Definisi/Definition & Nilai/Value \\
\hline 1 & $\mathrm{r}$ & $\begin{array}{l}\text { Tingkat pertumbuhan intrinsic / } \\
\text { Intrinsic growth rate }\end{array}$ & 1.51 \\
\hline 2 & q & $\begin{array}{l}\text { Koefisien kemampuan tangkap / } \\
\text { Catchability coefficient }\end{array}$ & 0,00047 \\
\hline 3 & K & Daya dukung perairan / Carrying capacity & 2,607 \\
\hline
\end{tabular}

Sumber: Hasil analisis data primer (2010) / Source: Primary data, 2010

Parameter ekonomi terdiri dari parameter biaya operasional penangkapan per trip dan rata-rata harga ikan per $\mathrm{kg}$. Rata-rata biaya operasional per trip masing-masing kapal yang berkunjung atau mendaratkan hasil tangkapannya di PPS Bitung diperoleh dari data primer. Jenis alat tangkap yang dominan mendaratkan ikan hasil tangkapan di PPS Bitung terdiri dari kapal dengan alat tangkap pole and line, purse seine dan tuna hand line. Kapal dengan alat tangkap pole and line dan tuna hand line umumnya menggunakan kapal bermotor, sedangkan armada dengan alat tangkap purse seine menggunakan motor tempel. Kapal dengan motor tempel tidak menggunakan bahan bakar solar sebagai bahan bakar utama. Oleh karena itu, ratarata biaya operasional yang digunakan sebagai parameter ekonomi diperoleh dari rata-rata biaya operasional kapal dengan alat tangkap pole and line dan tuna hand line. Rata-rata biaya operasional dengan adanya subsidi yaitu harga solar Rp 4.500 per liter adalah Rp 14,9 juta.

Tabel 5. Perbandingan Biaya Operasional Menurut Jenis Alat Tangkap di PPS Bitung, 2010.

Table 5. Comparison of Operational Cost by Fishing Gear Types in PPS Bitung, 2010.

\begin{tabular}{|c|c|c|c|c|}
\hline \multirow[b]{2}{*}{ Uraian/Items } & \multicolumn{4}{|c|}{ Jenis Alat Tangkap/ Fishing Gear Types } \\
\hline & $\begin{array}{l}\text { Pukat cincin/ } \\
\text { Purse seine }\end{array}$ & $\begin{array}{c}\text { Huhate/ } \\
\text { Pole and Line }\end{array}$ & $\begin{array}{l}\text { Pancing ulur } \\
\text { tuna 1/Tuna } \\
\text { Hand Line } 1\end{array}$ & $\begin{array}{c}\text { Pancing ulur } \\
\text { tuna 2/Tuna } \\
\text { hand line } 2\end{array}$ \\
\hline $\begin{array}{l}\text { Rata-rata ukuran kapal / } \\
\text { Average of vessel size }\end{array}$ & $\geq 5 \mathrm{GT}-<10 \mathrm{GT}$ & $\geq 30 \mathrm{GT}-<100 \mathrm{GT}$ & $\geq 5 \mathrm{GT}-<10 \mathrm{GT}$ & $\begin{array}{l}\geq 10 \mathrm{GT}- \\
<30 \mathrm{GT}\end{array}$ \\
\hline \multicolumn{5}{|l|}{$\begin{array}{l}\text { Rata-rata lama hari per trip: / } \\
\text { Average of day fish }\end{array}$} \\
\hline - Musim ikan / Harvest season & 1 & 3 & 8 & 10 \\
\hline - Musim biasa / Regular season & 1 & 5 & 10 & 11 \\
\hline - Musim paceklik / Bad season & 1 & 7 & 13 & 14 \\
\hline $\begin{array}{l}\text { Rata-rata biaya operasional per } \\
\text { trip dengan subsidi BBM (Rp) / } \\
\text { Average of operational cost with } \\
\text { solar subsidies }\end{array}$ & $2,279,430$ & $34,907,840$ & $4,497,369$ & $5,367,910$ \\
\hline $\begin{array}{l}\text { Rata-rata biaya operasional per } \\
\text { trip tanpa subsidi solar (Rp)/ } \\
\text { Average of operational cost } \\
\text { without solar subsidies }\end{array}$ & $2,789,850$ & $49,415,840$ & $5,366,088$ & $6,450,160$ \\
\hline $\begin{array}{l}\text { Penerimaan Kotor (Rp) / Gross } \\
\text { income }\end{array}$ & $5,451,600$ & $54,580,000$ & $14,096,750$ & $17,760,000$ \\
\hline
\end{tabular}


Rata-rata harga ikan yang digunakan dalam penelitian ini diperoleh dari data sekunder. Harga ikan yang digunakan adalah harga ikan dengan jumlah produksi dominan tahun 2009. Jenis ikan dominan yang didaratkan di PPS Bitung terdiri dari ikan layang, kembung, cakalang dan tuna. Rata-rata harga ikan tersebut adalah Rp 6.200 per kg.

\section{Dampak Pemberian Subsidi}

Dampak subsidi harga solar terhadap kelestarian sumber daya perikanan di Bitung dapat ditinjau dari perubahan jumlah effort dan kondisi stok ikan pada pemanfaatan maximum economic yield. Hal ini dilakukan karena pemberian subsidi merupakan salah satu instrumen ekonomi dalam pengelolaan sumber daya perikanan. Diduga dengan adanya pemberian subsidi, maka jumlah effort akan mengalami peningkatan sehingga laju pemanfaatan terhadap sumber daya perikanan tersebut akan semakin cepat.

Penggunaan parameter biologi dan ekonomi yang telah diperoleh sebelumnya dan berdasarkan metode analisis yang telah dikemukakan maka jumlah upaya penangkapan, jumlah hasil tangkapan dan besaran stok ikan dapat estimasi. Analisis dilakukan pada kondisi biaya operasional saat ini yaitu adanya subsidi harga solar dan kondisi pada saat harga solar tidak disubsidi (Rp 7.500 per liter). Jumlah upaya penangkapan yang diperbolehkan untuk melakukan penagkapan ikan pada lokasi fishing ground yang ada saat ini di Bitung adalah sebanyak 1.601 trip dengan adanya subsidi dan 1.600 trip tanpa subsidi. Jumlah upaya penangkapan ini lebih besar dibandingkan rata-rata jumlah upaya penangkapan aktual yang terjadi di PPS Bitung. Rata-rata jumlah upaya penangkapan aktual selama tahun 2005 sampai dengan tahun 2009 adalah 1.562 trip per bulan. Dalam rentang waktu 2005 sampai dengan 2009 , rata-rata jumlah upaya penangkapan mengalami fluktuasi, dimana jumlah upaya penangkapan tertinggi terjadi pada tahun 2008 sebesar 2.427 trip. Jumlah upaya penangkapan tertinggi ini terjadi karena banyaknya kapal one day fishing yang berkunjung.

Ditinjau dari jumlah upaya penangkapan, maka pemberian subsidi tidak menyebabkan semakin meningkatnya jumlah upaya penangkapan pada kondisi MEY secara signifikan. Dalam hal ini, adanya peningkatan biaya operasional sekitar 15\%, maka jumlah upaya penangkapan tidak menunjukkan jumlah yang semakin menurun secara drastis.

Pada tabel 6 dapat diketahui bahwa jumlah hasil tangkapan yang di daratkan di PPS Bitung tidak mengalami perubahan karena adanya perubahan biaya operasional dengan dan tanpa subsidi. Berdasarkan data aktual, jumlah hasil tangkapan yang didaratkan di PPS Bitung mengalami peningkatan setiap

Tabel 6. Jumlah Biomas, Hasil Tangkapan, Upaya Penangkapan dan Rente Ekonomi Pemanfaatan Sumber Daya Perikanan Kondisi MEY di Bitung, 2010.

Table 6. Biomass, Catch, Effort and Economic Rent of Fisheries Exploitation in MEY Condition at Bitung, 2010.

\begin{tabular}{clcrr}
\hline $\begin{array}{c}\text { Simbol / } \\
\text { Symbol }\end{array}$ & Definisi / Definition & $\begin{array}{c}\text { Satuan / } \\
\text { unit }\end{array}$ & $\begin{array}{c}\text { Dengan Subsidi / } \\
\text { With Subsidy }\end{array}$ & $\begin{array}{c}\text { Tanpa Subsidi / } \\
\text { Without Subsidy }\end{array}$ \\
\hline X & Stok ikan / Biomass & Ton & $1,306.07$ & $1,307.01$ \\
H & Hasil tangkapan / Catch & Ton & 982.80 & 982.80 \\
E & Upaya penangkapan / & unit & 1,601 & 1,600 \\
& Effort & Rp & $6,069,486,937$ & $6,060,706,307$ \\
\hline
\end{tabular}

Sumber: Hasil analisis data primer, 2010 / Source: Primary data, 2010 
tahunnya. Rata-rata jumlah hasil tangkapan pada tahun 2005 adalah 504 ton per bulan, tahun 2006 adalah 810 ton per bulan. Ratarata jumlah produksi periode Januari 2005 sampai dengan Desember 2009 adalah 993,44 ton per bulan. Jumlah produksi aktual ini telah melebihi jumlah produksi menurut estimasi MEY, hal ini disebabkan karena adanya pergeseran pengguna armada penangkapan yang dilakukan oleh nelayan. Periode sampai dengan tahun 2007 nelayan masih dominan menggunakan perahu tanpa motor dengan jangkauan fishing ground yang lebih dekat. Periode selanjutnya nelayan telah lebih banyak menggunakan kapal dengan alat tangkap tuna hand line yang diadopsi dari nelayan negara tetangga. Jumlah hasil tangkapan yang semakin meningkat tidak disebabkan oleh semakin banyaknya trip penangkapan, melainkan karena semakin lamanya jumlah hari melaut per trip.

Dengan adanya pengurangan upaya penangkapan karena tanpa ada subsidi, maka stok ikan atau jumlah biomas ikan meningkat sebanyak 0,94 ton per bulan atau hanya $0,07 \%$. Peningkatan ini tidak menunjukkan angka yang signifikan dibandingkan terhadap perubahan biaya operasional penangkapan dengan dan tanpa subsidi. Perbedaan rente ekonomi yang dapat diterima dari pemanfaatan sumber daya perikanan berkurang sebesar Rp 8,78 juta jika subsidi dihapus. Dengan demikian dapat dikatakan bahwa adanya pemberian subsidi tidak menyebabkan terkurasnya sumber daya perikanan di Bitung, karena dengan adanya pengurangan biaya operasional tidak menyebabkan peningkatan jumlah upaya penangkapan secara signifikan.

Tanpa adanya subsidi maka nelayan harus menyediakan modal untuk melaut lebih besar lagi, karena komponen biaya BBM meliputi lebih dari $50 \%$ total biaya yang dibutuhkan untuk melakukan penangkapan. Semakin besar armada penangkapan yang digunakan, maka jumlah BBM yang dibutuhkan semakin banyak. Tanpa adanya subsidi solar, maka nelayan yang menggunakan alat tangkap pole and line harus menambah penyediaan modal untuk pembelian BBM sebanyak $42 \%$ dari total biaya operasional yang dikeluarkan. Nelayan yang menggunakan alat tangkap tuna hand line harus menambah penyediaan modal sebesar $20 \%$ dari biaya operasional yang telah dikeluarkan. Oleh karena itu, subsidi sangat diperlukan nelayan Bitung untuk dapat terus melakukan penangkapan ikan. Tanpa adanya subsidi solar diduga banyak nelayan Bitung tidak dapat melanjutkan usaha penangkapan, sedangkan potensi sumber daya ikan yang tersedia cukup besar yang harus dimanfaatkan oleh nelayan untuk memenuhi kebutuhan hidup. Jika potensi sumber daya perikanan tidak dimanfaatkan oleh nelayan setempat, maka potensi yang ada akan dimanfaatkan oleh nelayan negara lain secara illegal.

Dampak pemberian subsidi kepada nelayan melalui subsidi harga solar terhadap kelestarian sumber daya perikanan di Bitung dilihat dengan menggunakan analisis sistem dinamik. Analisis sistem dinamik dikembangkan dengan bantuan software VENSIM versi 5.5. Variabel yang digunakan dalam sistem dinamik ini terdiri dari stok variable, flow variable dan konstanta. Stok variabel atau variabel stok terdiri dari variabel sumber daya ikan di Bitung (SDI), effort yaitu upaya penangkapan dan usaha. Variable flow berupa tingkat pertumbuhan stok ikan, laju perubahan effort, penerimaan usaha dan biaya penangkapan. Konstanta berupa harga ikan, jumlah hasil tangkapan, $r, K, q$, solar dan harga solar serta biaya penangkapan lainnya. Simulasi dilakukan terhadap 3 kondisi yang berbeda yaitu kondisi saat ini (subsidi), adanya peningkatan harga solar (non subsidi) dan pada kondisi tidak adanya pembatasan jumlah effort (open akses). Pada simulasi subsidi dan non subsidi dilakukanpembatasan terhadap jumlah effort. Simulasi open akses dilakukan untuk melihat dinamika effort yang akan terjadi tanpa adanya pengelolaan oleh pemerintah. Harga solar untuk simulasi open accses adalah Rp 4.500 per liter. 
Pada variabel SDI akan terlihat dinamika stok ikan dengan adanya pertumbuhan ikan dan laju ekstraksi. Fungsi pertumbuhan ikan menggunakan fungsi pertumbuhan logistik dan laju ekstraksi atau penangkapan menggunakan model Cobb Douglas. Variabel effort untuk melihat dinamika upaya penangkapan yang dipengaruhi oleh harga ikan, q, stok ikan dan delta peningkatan jumlah effort. Variabel usaha yang dimaksud disini adalah keuntungan usaha yang dapat diperoleh dengan dinamika penerimaan dan biaya penangkapan. Penerimaan ditentukan oleh jumlah hasil tangkapan dan harga ikan, biaya ditentukan oleh jumlah kebutuhan solar, harga solar dan biaya lainnya dalam melakukan penangkapan ikan selain biaya solar.

Hasil analisis sistem dinamik tersebut dapat dilihat dari dinamika jumlah upaya penangkapan, stok ikan, jumlah hasil tangkapan dan usaha penangkapan ikan. Pada kondisi aktual rata-rata jumlah upaya penangkapan adalah 1.562 trip, trajectory effort dimulai dari angka tersebut. Pada kondisi subsidi yaitu harga solar Rp. 4.500 per liter, maka jumlah effort mengalami peningkatan sebesar 18 trip per bulan. Kondisi ini berhimpit dengan simulasi adanya peningkatan harga solar menjadi Rp. 7.500 per liter.

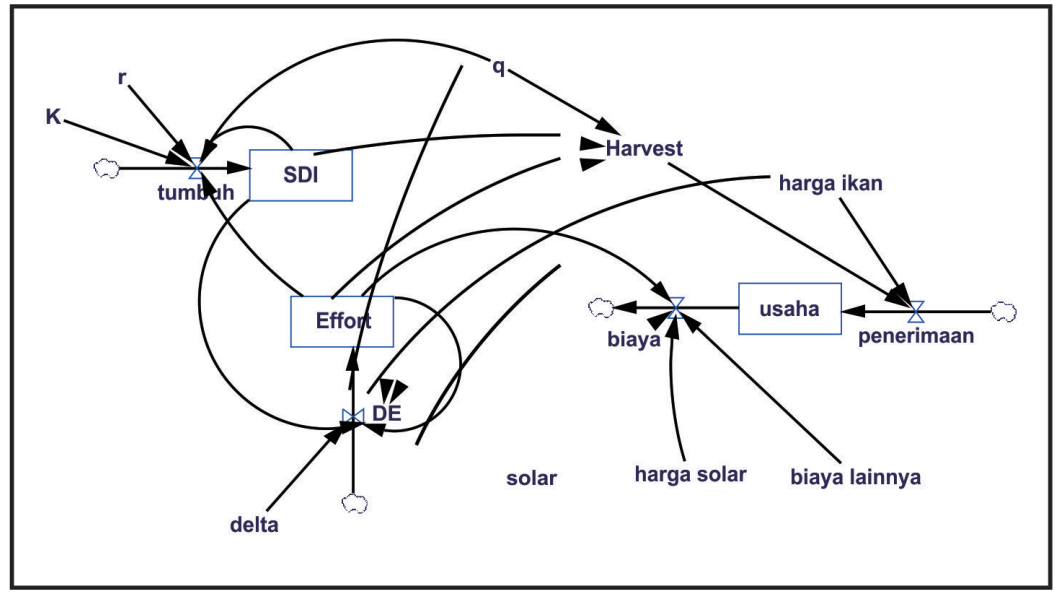

Gambar 1. Diagram Simulasi Sistem Dinamis.

Figure 1. Simulation Diagram of Dynamic System.

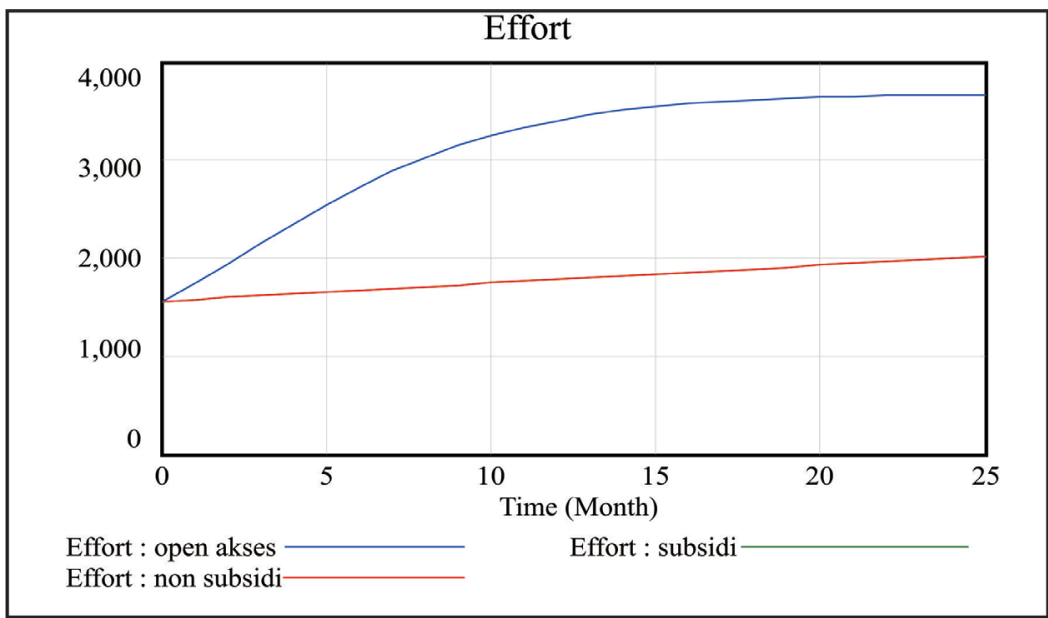

Gambar 2. Garis Trajektori Jumlah Upaya Penangkapan di Bitung. Figure 2. Trajectory Path of Effort in Bitung. 
Dengan demikian dapat dikatakan bahwa dengan adanya peningkatan harga solar tidak menyebabkan penurunan jumlah effort. Simulasi ketiga dapat terlihat bahwa jika effort dibiarkan bebas pada kondisi open akses, maka akan terjadi peningkatan jumlah effort secara signifikan sampai dengan akhir periode analisis.

Stok ikan mengalami penurunan sejalan dengan adanya peningkatan jumlah upaya penangkapan. Nilai awal (inisial value) stok ikan adalah besaran jumlah stok ikan pada rezim MEY yaitu 1.306 ton. Pada simulasi subsidi dan non subsidi penurunan jumlah stok ikan selama periode analisis menuju jumlah produksi optimal yaitu 980 ton per bulan. Rata-rata penurunan jumlah produksi adalah 15 ton per bulan. Hal ini disebabkan karena adanya peningkatan jumlah upaya penangkapan melebihi jumlah effort optimal. Pada simulasi open accses, maka besaran stok ikan mengalami penurunan terus sampai mendekati angka nol. Hal ini disebabkan karena penangkapan yang dilakukan lebih besar dari tingkat pertumbuhan ikan. Simulasi non subsidi tidak menunjukkan perbedaan yang nyata dengan kondisi subsidi, sehingga dapat dikatakan bahwa adanya pemberian subsidi bahan bakar solar tidak menyebabkan terkurasnya sumber daya perikanan di Bitung.

Jumlah hasil tangkapan ditentukan oleh jumlah upaya penangkapan, koefisien kemampuan alat tangkap dan ketersediaan stok sumber daya ikan. Adanya peningkatan upaya penangkapan maka jumlah hasil tangkapan akan mengalami peningkatan sampai pada kondisi optimal pemanfaatan. Jika upaya penangkapan telah melebihi kondisi optimal pemanfaatan, maka hasil tangkapan akan semakin menurun, karena semakin berkurangnya ketersediaan stok sumber daya ikan itu sendiri. Supaya jumlah produksi dapat berlangsung terus pada kondisi maksimal, maka jumlah upaya penangkapan harus dibatasi sampai pada kondisi optimal MEY. Pada simulasi subsidi dan non subsidi, jumlah hasil tangkapan mengalami peningkatan sampai dengan periode keempat dan selanjutnya mengalami penurunan dengan laju penurunan yang kecil. Sampai dengan akhir periode analisis jumlah hasil tangkapan masih berada pada jumlah produksi optimal.

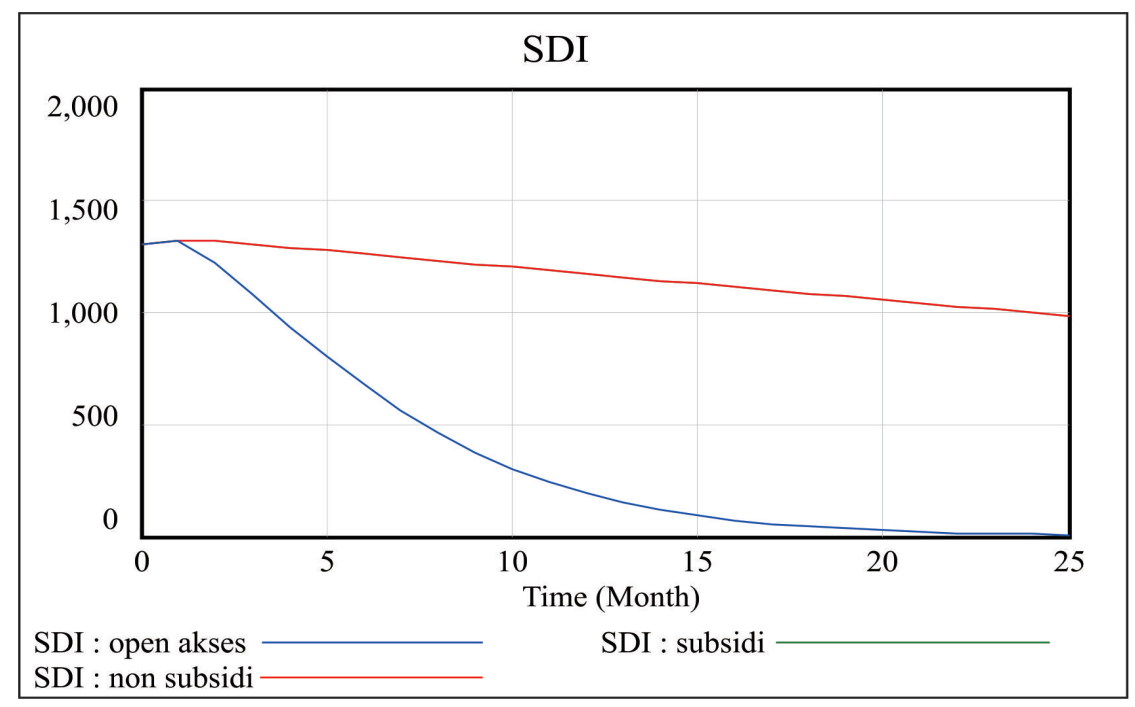

Gambar 3. Garis Trajektori Stok Ikan di Bitung, 2010.

Figure 3. Trajectory Path of Fish Stock in Bitung, 2010. 


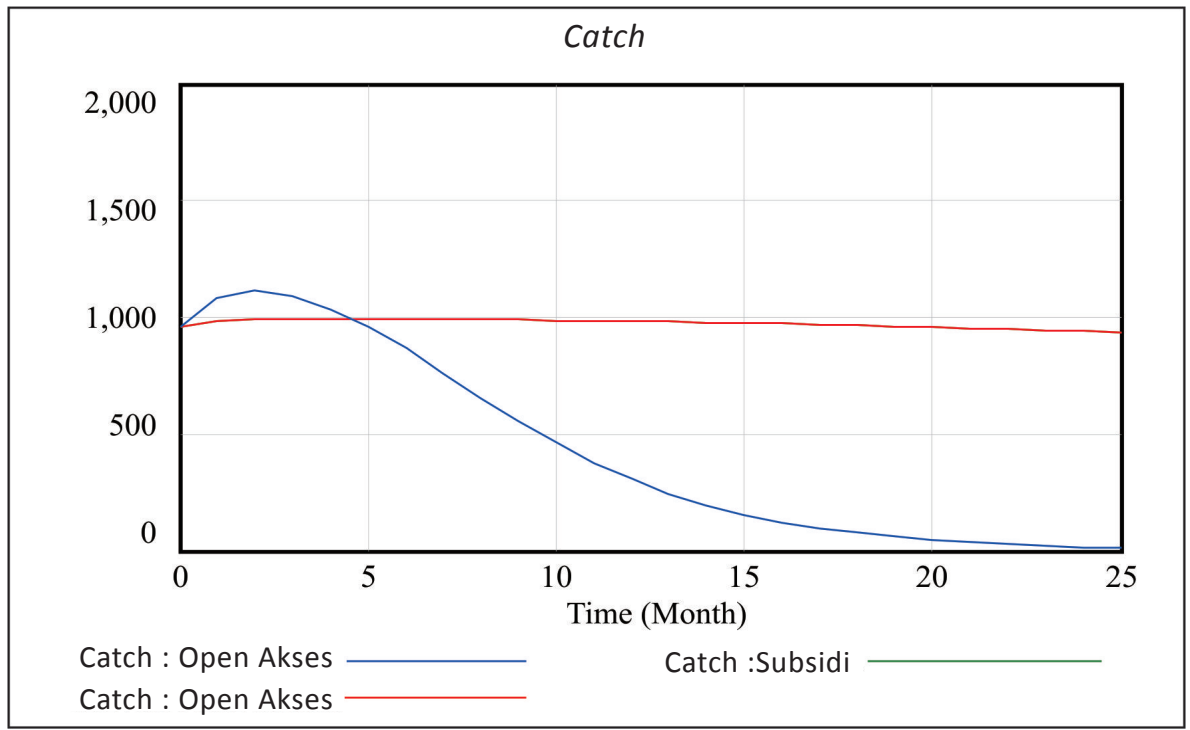

Gambar 4. Trajektori Jumlah Hasil Tangkapan di Bitung.

Figure 4. Trajektory Path of Fish Production in Bitung.

Pada simulasi open accses, jumlah hasil tangkapan akan mengalami peningkatan sesuai dengan ketersediaan stok, selanjutnya mengalami penurunan drastis dengan adanya penambahan jumlah upaya penangkapan yang melebihi kondisi optimal. Periode selanjutnya akan terus mengalami penurunan karena ketersediaan stok ikan terus mengalami penurunan akibat tingginya tingkat pemanfaatan dibandingkan tingkat pertumbuhan ikan. Penerimaan nelayan atau seluruh pelaku perikanan di Bitung menunjukkan tren yang sama dengan jumlah hasil tangkapan. Penerimaan diperoleh dari besarnya jumlah hasil tangkapan dikalikan dengan harga ikan. Adanya tren yang sama antara jumlah produksi dengan penerimaan disebabkan karena dalam penelitian ini menggunakan harga konstan yaitu $\mathrm{Rp} 6.200$ per kg.

Rente dari usaha perikanan tangkap ditentukan oleh besarnya penerimaan dikurangi dengan biaya. Pada simulasi subsidi, rente usaha menunjukkan nilai yang positif sampai dengan akhir periode analisis. Hal ini disebabkan, karena penerimaan usaha dapat menutupi seluruh biaya yang dikeluarkan. Simulasi non subsidi yaitu dengan adanya peningkatan harga solar menjadi Rp 7.500 per liter, menyebabkan besarnya biaya penangkapan, maka rente ekonomi yang diperoleh bernilai negatif mulai dari awal sampai dengan akhir periode. Penerimaan usaha dari penjualan hasil tangkapan dengan harga 6.200 per kg tidak dapat menutupi biaya penangkapan dengan adanya peningkatan harga solar. Simulasi open akses menunjukkan nilai rente yang positif pada awal periode dan selanjutnya bernilai negatif karena semakin besarnya jumlah upaya penangkapan dan semakin kecilnya jumlah hasil tangkapan. Peningkatan harga solar atau penghapusan subsidi solar akan menyebabkan rendahnya rente ekonomi dari usaha perikanan tangkap. Subsidi harga solar sangat dibutuhkan oleh nelayan untuk melanjutkan usaha perikanan tangkap dan dan subsidi ini tidak menyebabkan terkurasnya stok sumber daya ikan di Bitung. Hal ini disebabkan karena tingkat eksploitasi yang ditinjau dari jumlah effort aktual masih lebih rendah dibandingkan jumlah effort pada kondisi MEY. 


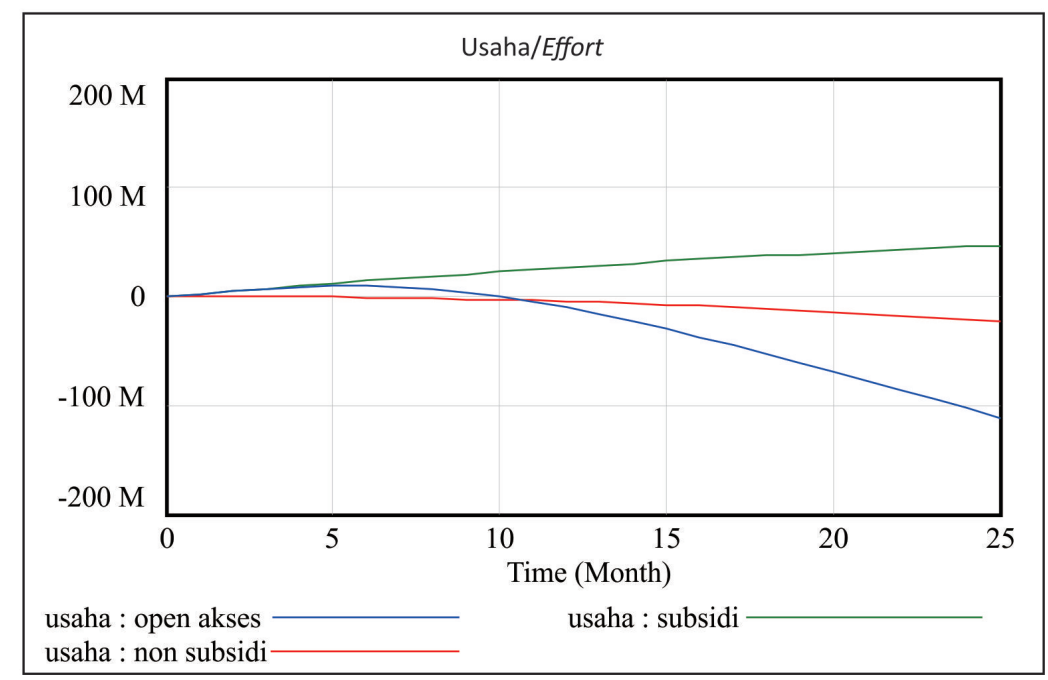

Gambar 5. Trajektori Rente Ekonomi Usaha Perikanan Tangkap di Bitung.

Figure 5. Trajektory Path of Fishery Economic Rent in Bitung.

\section{KESIMPULAN DAN IMPLIKASI KEBIJAKAN}

\section{Kesimpulan}

Parameter biologi yang diperoleh terdiri dari tingkat pertumbuhan intrinsik ikan $1,51 \%$, koefisien kemampuan tangkapan alat tangkap yang terdapat di Bitung yaitu 0,00047 dan daya dukung perairan terhadap sumber daya perikanan adalah 2.607 ton per tahun. Jumlah upaya penangkapan pada kondisi MEY adalah 1.601 trip per bulan, jumlah hasil tangkapan yang diperbolehkan 982,80 ton dan ketersediaan stok sumber daya ikan 1.306 ton. Tanpa adanya subsidi harga solar (harga solar Rp 7.500 per liter) maka jumlah upaya penangkapan yang diperbolehkan 1.600 dan ketersediaan stok menjadi 1.307 ton. Pemberian subsidi harga solar tidak menyebabkan peningkatan jumlah upaya penangkapan dibandingkan dengan tanpa subsidi. Subsidi harga solar ini hanya menyebabkan semakin tingginya tingkat keuntungan yang diperoleh oleh nelayan, karena semakin berkurangnya biaya operasional. Dalam jangka panjang, pemberian subsidi harga solar terhadap nelayan di Bitung, tidak menyebabkan terkurasnya sumber daya perikanan di Bitung.

\section{Implikasi Kebijakan}

Subsidi perikanan dalam hal ini subsidi terhadap harga solar tidak menyebabkan terkurasnya sumber perikanan di Bitung. Disamping itu, subsidi tersebut sangat diperlukan untuk keberlanjutan usaha. Tanpa adanya subsidi harga solar, maka nelayan tidak dapat melanjutkan usaha penangkapan ikan di Bitung. Rendahnya tingkat pemanfaatan sumber daya perikanan di Bitung, maka sumber daya tersebut akan dimanfaatkan oleh nelayan tetangga karena Bitung merupakan wilayah perbatasan dengan Filipina. Pada kondisi saat ini dengan rata-rata jumlah effort 1.562 trip per bulan, sumber daya perikanan di wilayah perbatasan masih sangat memungkinkan untuk dimanfaatkan oleh nelayan negara tetangga.

\section{DAFTAR PUSTAKA}

Anonimous, 2010. Laporan Tahunan Pelabuhan Perikanan Samudera Bitung. Pelabuhan Perikanan Samudera Bitung. Bitung.

,2010. Buku Statistik Pelabuhan Perikanan Samudera Bitung. Pelabuhan Perikanan Samudera Bitung. Bitung. 
Fauzi, A. 2005. Kebijakan Perikanan dan Kelautan Isu, Sintesis dan Gagasan. Gramedia Pustaka Utama. Jakarta.

Mathew, S. 2003. Fishing for Subsidies. Samudra, Nov. 2003. ICSF.

Schaefer, M.B. 1954. Some Aspect of the Dynamics of Populations Important to the Management of Commercial Marine Fishery Bull. Interm-Am.

Srchrank, W.E., 2001. Subsidies for Fisheries. A. Review of Concept. In: FAO Papers Presented at The Expert Consultation on Economic Incentive and Responsible Fisheries Rome, 28 November 1 Desember 2000, Rome, 11-40
Tinungki, G. M. 2005. Evaluasi Model Produksi Surplus Dalam Menduga Hasil Tangkapan Maksimum Lestari Untuk Menunjang Kebijakan Pengelolaan Perikanan Lemuru Di Selat Bali. Disertasi. Tidak dipublikasikan. Sekolah Pascasarjana - Institut Pertanian Bogor.

Wirabuana, A. 2005. Penerapan Model Simulasi Sistem Dinamis pada Analisis Biaya Total Non Produksi sebagai Pengaruh dari Sektor Produksi dan Sumberdaya Manusia. Tesis. Program Studi Teknik Industri Fakultas Sains dan Teknologi. Universitas Islam Negeri Sunan Kalijaga, Surabaya. 